\title{
摩擦による免震装置の相対変位低減に関する実験的研究*
}

\author{
新谷真 功*1, 田口直 知 $^{* 2}$, 服部雄 一*3
}

\section{Experimental Study on Isolation Device for Decrease of Displacement by Using Control of Friction}

\author{
Masanori SHINTANI*4, Naoya TAGUCHI and Yuichi HATTORI \\ ${ }^{* 4}$ Department of Mechanical Engineering, University of Fukui, \\ 3-9-1 Bunkyo, Fukui-shi, Fukui, 910-8507 Japan
}

\begin{abstract}
This paper deals with development of new isolation device by using friction force. This isolation device carries out reduction of horizontal relative displacement by using friction force. The isolation device uses a slope plate. The Friction force acts on the slope plate. The restoring-force is given to the isolation device from the compression spring attached to the base. In the equation of motion of analytical model, the friction force changes in proportion to displacement. The restoring-force is also proportional to displacement. The restoring-force always works in the direction of a center. Therefore, the friction force and restoring-force are proportional to displacement. Simulation analysis is calculated on various conditions using the analysis model. Condition reducing both response acceleration and displacement effectively is examined. Furthermore, an experiment is conducted using the experimental model. The experimental results are compared with analysis results. The performance of the isolation device is examined. The validity of the performance is shown.
\end{abstract}

Key Words: Earthquake, Isolation Device, Friction Force, Vibration Experiment, Inclination Friction Plate

\section{1. 緒言}

毎年，世界各地で地震が起きており，多くの被害 が出ている. 地震による被害を防止するため, 構造物 を強く造って地震に耐える，而震構造の研究が長年さ れてきた. しかし，1995年に起きた兵庫県南部地震で 被害が小さかった免震構造が大きな注目を浴びるよう になった(l). 免震構造とは，構造物と地盤の間に積層 ゴム支承やダンパー等の装置を設置して，地震の激し い摇れを低减し, 地震動に対する構造物の応答加速度 を低減するものであるき．しかし，免震構造物では， 地震時に構造物と地盤の間に大きな相対変位が生 じてしまう。.大きな地震動に対しては，相対変位 が $0.2 \mathrm{~m}$ から $0.4 \mathrm{~m}$ 程度生じることが予想される(2). そのため, 地震時に他の構造物と衝突しないため に，ある程度の距離を確保しなければならない(3) (4)

免震装置は主に積層ゴムと，减衰を増大させるた めのダンパーで構成されている，そこで，支承に減衰 力，復元力を付与することにより，支承とダンパーを

\footnotetext{
* 原稿受付 2007 年 3 月 26 日.

*1 正員, 福井大学大学院工学研究科(茂 910-8507 福井市文京 3-9-1).

*2 学生員, 福井大学大学院機械工学専攻

*3 准員, NTN (株) (焉 438-8510 磐田市東貝塚 1578).

E-mail : shintani@ mech.fukui-u.ac.jp
}

一体型にできれば, 免震装置構造の簡略化やコスト低 下につながり，有意義であると考えられる．本研究 では，摩擦力と圧縮ばねの復元力を利用した支承とダ ンパーが一体型の免震装置を提案する.このような免 震装置に対し，シミュレーション解析を行った結果， 応答加速度, 相対変位の低減が確認された. そこで, 本報では，実験的に本装置の免震性能を検討する．ま た，実験装置と同じ条件で解析を行い，実験結果と比 較する.

\section{2. 実験}

\section{$2 \cdot 1$ 実験装置 図 1 は, 実験装置の写真を示し} ている，実験装置は，水平 1 方向のみに運動する. $\mathrm{H}$ 型鋼にリニアガイドを取り付け，その上に摩擦面を取 り付けている. さらに，下方から復元力を得られるよ うに, フランジによって, 鋼球を取り付けた圧縮ばね を固定する．また，地震時には，摩擦面と鋼球の閒に 摩擦力が生じる. 復元力は常に摩擦面の中心方向に働 き, 摩擦力は速度と反対方向に働く. 復元力が常に中 心方向に働くことによって，地震後には，摩擦面は中 央部に戻るようになっている，図 2, 図 3 に実験装置 上部の摩擦面と, 実験装置下部の圧縮ばねの写真を示 す. 摩擦面の材質は軟鋼で, 圧縮ばねに取り付けた鋼 球の材質は炭素鋼である. 摩擦面は, ワイヤ一カッタ 
一で加工した. 摩擦面の形状は, 図 4 に示すように, 曲面と斜面で構成されており，中心から $0.01 \mathrm{~m}$ 以内ま では曲面, $0.01 \mathrm{~m}$ を超えると斜面の形状をしている. なお，曲面の曲率半径は $0.06 \mathrm{~m}$ とする，また，図 5 は 実験装置の下部の圧縮ばねの詳細を示している.

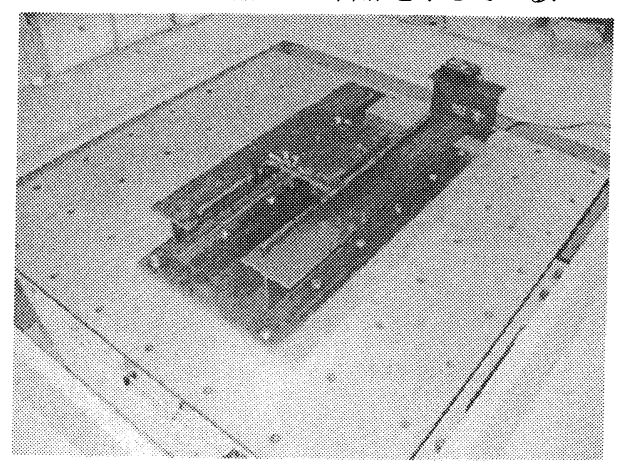

Fig.1 Experimental apparatus

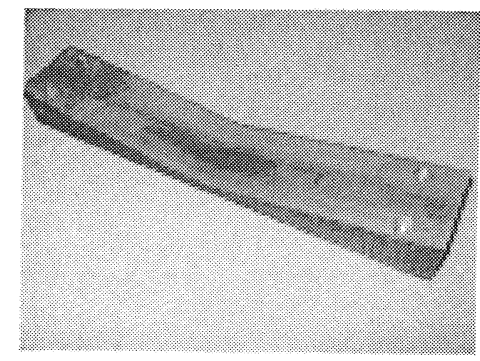

Fig.2 Experimental apparatus (upper part, friction surface)

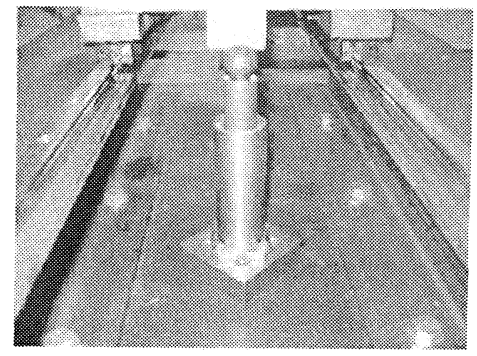

Fig. 3 Experimental apparatus (lower part, the compression spring with the steel ball)

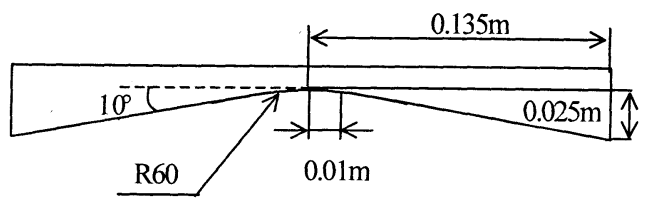

Fig.4 Experimental apparatus

(upper part, friction surface, detail drawing)

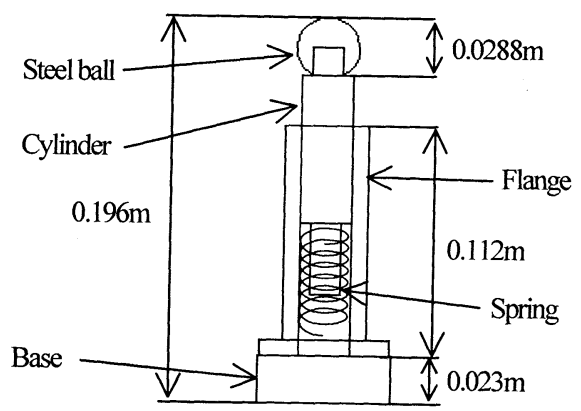

Fig.5 Experimental apparatus

(lower part, the compression spring with the steel ball, detail drawing)

$2 \cdot 2$ 実験方法 実験は, 実験用免震装置を振動 台に設置して，水平 1 方向のみに加振して行う. 図 6 は免震装置の詳細を示している. 図6のように, 振動 台の入力加速度, 免震装置の応答加速度を加速度ピッ クアップで, 振動台と免震装置の相対変位をレーザー 変位計で計測する。なお，実験には JMA Kobe NS 波 (1995年兵庫県南部地震), Taft NS 波(1952 年 Ken Country 地震)の地震波形を用いる. ただし, 振動台の最大許 容変位を考慮して，JMA Kobe NS 波は $45 \%$ の大きさの 入力加速度を入力する．なお，実験には，表 1 に示す 4 種類の圧縮ばねを用いる.

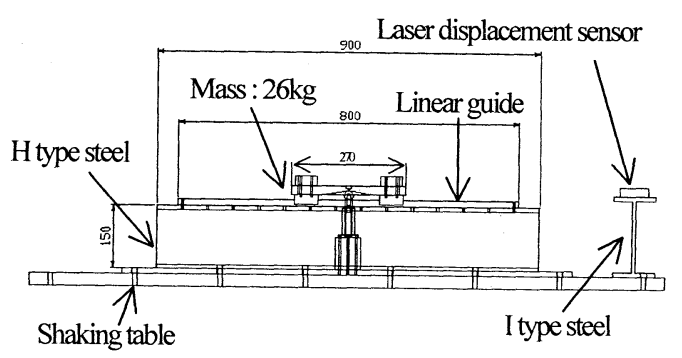

Fig.6 Experimental apparatus (detail drawing)

Table 1 Compression spring constant

\begin{tabular}{|l|c|c|c|}
\hline \multicolumn{4}{|c|}{ Compression spring constant $(\mathrm{N} / \mathrm{m})$} \\
\hline 4920 & 5310 & 8050 & 10000 \\
\hline
\end{tabular}

\section{$2 \cdot 3$ 実験結果 以上の実験装置および実験方法} により, 実験を行った. 図 7, 図 8 はそれぞれ，JMA Kobe NS 波と Taft NS 波の振動台の入力加速度波形を示 している. また, 実験結果の一例として, 圧縮ば水定 数を $4920 \mathrm{~N} / \mathrm{m}$ とし，JMA Kobe NS波を用いて得られた 
実験結果を図9に，Taft NS波を用いて得られた実験結 果を図 10 に示す．図 9 では, 応答加速度は約 $33 \%$ に,

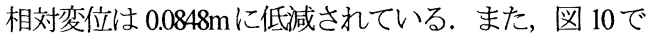
は，応答加速度は約 36\%に，相対変位は $0.0193 \mathrm{~m}$ に低 減されている。 これらの実験結果より，本研究のモデ ルの免震性能が確認された. また, 摩擦係数は, ばね ばかりで引っ張る方法で求める. 支承材として用いる リニアガイドにも摩察力が生じると考えられるため, 同様に測定する. まず，リニアガイドに働く摩擦力を 調べるため, 摩擦面を取り外した状態で測定を 2 回行 った，次に，摩擦面を取り付け，ば的定数が $4920 \mathrm{~N} / \mathrm{m}$ の圧縮ばねを $0.025 \mathrm{~m}$ 圧縮させた状態で測定を行った。 この值とリニアガイドの摩擦力の差を, 摩擦面に作用 する摩擦力とする. これらの測定結果を表 2 に示寸. ばねばかりによって摩擦力の計測を行った結果, 摩擦 面に作用する静摩擦係数の平均は 0.147 , リニアガイ

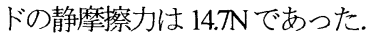

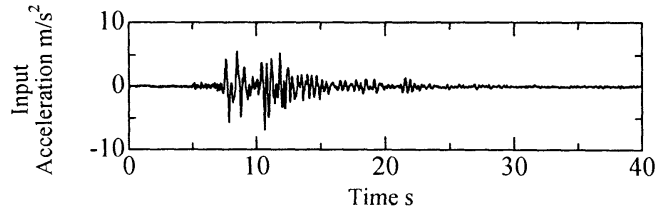

Fig.7 Input acceleration (JMA Kobe NS, $\max =6.94 \mathrm{~m} / \mathrm{s}^{2}$ )

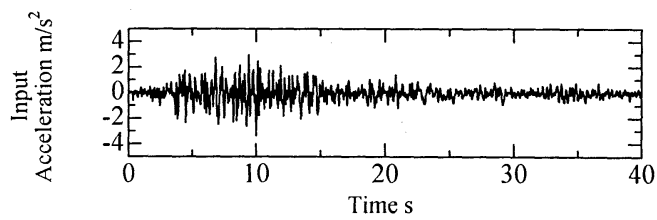

Fig.8 Input acceleration (Taft NS, $\max =3.35 \mathrm{~m} / \mathrm{s}^{2}$ )
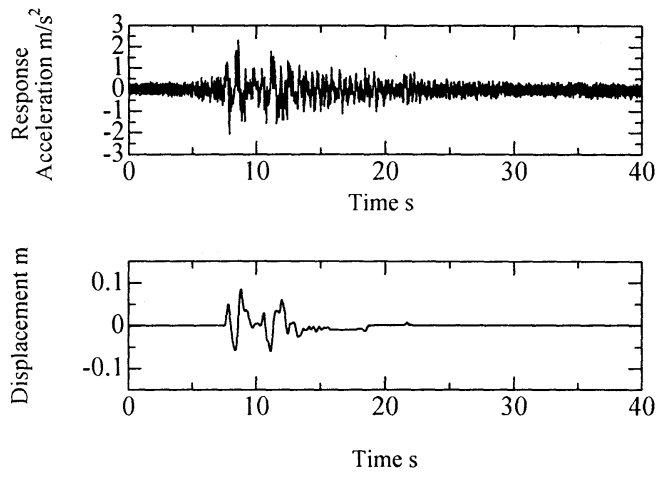

Fig.9 Response acceleration and displacement of experimental result

(JMA Kobe NS, $\max =2.29 \mathrm{~m} / \mathrm{s}^{2}, \quad 0.0848 \mathrm{~m}$ )
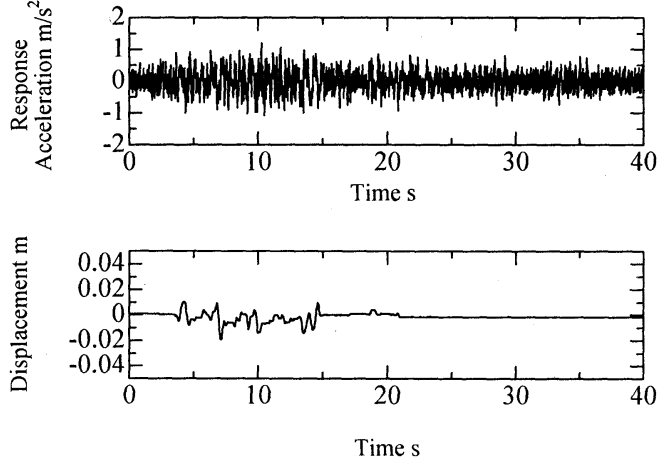

Fig.10 Response acceleration and displacement of experimental result

(Taft NS, $\max =1.20 \mathrm{~m} / \mathrm{s}^{2}, \quad 0.0193 \mathrm{~m}$ )

Table 2 Friction force

\begin{tabular}{|c|c|c|}
\hline $\begin{array}{c}\text { Spring constant } \\
(\mathrm{N} / \mathrm{m})\end{array}$ & Friction froce $(\mathrm{N})$ & $\begin{array}{c}\text { Coefficient of } \\
\text { friction }\end{array}$ \\
\hline Non-spring & 14.7 & \\
\hline 4920 (first time) & 33.3 & 0.143 \\
\hline 4920 (second time) & 32.3 & 0.151 \\
\hline
\end{tabular}

\section{3. シミュレーション解析}

$3 \cdot 1$ 解析モテル 実験結果之解析結果を比較す るため，実験装置と同様の条件下でシミュレーション 解析を行う. 本研究の解析モデルは, 図11のような 1 質点系とし，摩擦面は，曲面と斜面て構成されている。 摩擦面に作用する力は, 圧縮ばねによる復元力 $\mathrm{kg} \sin \theta$ と摩擦力 $\mu h \cos \theta$ に分解される.ここで, $y$ は圧縮ばね の圧縮量， $\theta$ は摩擦面の角度を表している．また，実 験装置に，支承材として使用するリニアガイドにも， 摩擦力が生じると考えられる. そのため, 図 11 の解 析モデルに対して，水平方向のみに加速度を入力した ときの運動方程式は，免震装置に滑りが生じないとき (Phase 1)と滑りが生じるとき(Phase 2)に場合分けし，以 下の式を導出した.

i)Phase 1:免震装置に滑りが生じないとき

$$
x=\text { const } . \quad \dot{x}=0
$$

また，相対加速度 $\ddot{x}=0$ なので，

$$
\ddot{z}=\ddot{a}
$$

ii)Phase2:免震装置に滑りが生じるとき

動摩擦係数を $\mu_{d}$ とすると,

$$
\ddot{x}+\frac{k y \sin \theta \cos \theta}{m}+\frac{\mu_{d} k y \cos ^{2} \theta}{m}+\frac{F_{1}}{m}=-\ddot{a} \cdots \cdots \cdot(3)
$$


ここで, 第 3 項と第 4 項には速度の符号を反転させる 関数 $\operatorname{sgn}(\dot{x})$ を掛けて, 抵抗力として働くようにして いる. なお， $F_{l}$ は，リニアガイドの摩擦力を示してい る.

iii) 切り替え条件: Phase 1 と Phase 2 との切り替え条件は, 免震装置に加わる復元力, 摩擦力と外力の大小関係か ら次に示す式となる.

Phase 1 から Phase 2への切り替え条件は, 静摩擦係数 を $\mu_{s}$ とすると,

$$
\left|\ddot{a}+\frac{k y \sin \theta \cos \theta}{m}\right| \geq \frac{\mu_{s} k y \cos ^{2} \theta}{m}+\frac{F_{l}}{m}
$$

となり, Phase 2から Phase 1への切り替え条件は, 次の ようになる.

$$
\begin{aligned}
& x=\text { const }, \quad \dot{x}=0 \\
& \left|\ddot{x}+\ddot{a}+\frac{k y \sin \theta \cos \theta}{m}\right| \leq \frac{\mu_{d} k y \cos ^{2} \theta}{m}+\frac{F_{l}}{m}
\end{aligned}
$$

また, 曲面, 斜面の 2 つ摩擦面によって式(3), (4), (5)で示寸圧縮ばねの圧縮量 $y$ と摩擦面の角度 $\theta$ が異な る. 曲面の場合の $y$ と $\theta$ を図 12, 図 13 から, 斜面の 場合の $y$ と $\theta$ を図 14から導出し, 以下に示す。

a)曲面 $(0 \mathrm{~m}<|x|<0.01 \mathrm{~m})$

$$
\begin{aligned}
& y=r-\sqrt{r^{2}-x^{2}}+b \\
& \theta=\arcsin \frac{x}{r}
\end{aligned}
$$

b)斜面 $(0.01 \mathrm{~m} \leqq|x|)$

$$
\begin{aligned}
& y=x \cdot \tan \theta+b \\
& \theta=10^{\circ}
\end{aligned}
$$

ただし,$m$ : 質量 $(26 \mathrm{~kg}), \theta$ : 摩擦面の角度 $\left(10^{\circ}\right), k$ : 圧縮ばね定数, $\mu_{s}$ : 静摩擦係数, $\mu_{d}$ : 動摩擦係数, $b$ : 初期圧縮 $(0.005 \mathrm{~m}), y$ : ばねの圧縮量, $r$ :曲率半径 $(0.06 \mathrm{~m}), x$ : 相対変位, $\dot{x}$ : 相対速度, $\ddot{x}$ : 相対加速度, $\ddot{a}$ : 入力加速度, とする. 実験結果より得られた摩 擦力を静摩擦力とする．また，ばねばかりで動摩擦 力を計測するのは困難であるため, 動摩擦力を様々 な值に変化させ解析を行い, 動摩擦力を推定し, 動 摩擦係数を算出した. 摩擦面に作用する動摩擦係数 を 0.08 , リニアガイドの動摩擦力を $6.0 \mathrm{~N}$ と任意に 設定し, 解析を行う. 表 3 は, 解析に用いる摩擦力 を示している，摩擦面の摩擦係数およびリニアガイ ドの摩擦力は, 解析モデルが静止している状態で静
摩擦，動いている状態では動摩擦で運動する，なお， 解析には Runge-Kutta-Gill 法を用いる. さらに, 摩擦 面の上下方向の振動は無視し, 水平 1 方向のみにつ いて解析を行う。

Table 3 Friction force

\begin{tabular}{|c|c|}
\hline Coefficient of kinetic friction & 0.08 \\
\hline Coefficient of static friction & 0.147 \\
\hline Kinetic friction force of linear guide $(\mathrm{N})$ & 6.0 \\
\hline Static friction force of linear guide $(\mathrm{N})$ & 14.7 \\
\hline
\end{tabular}

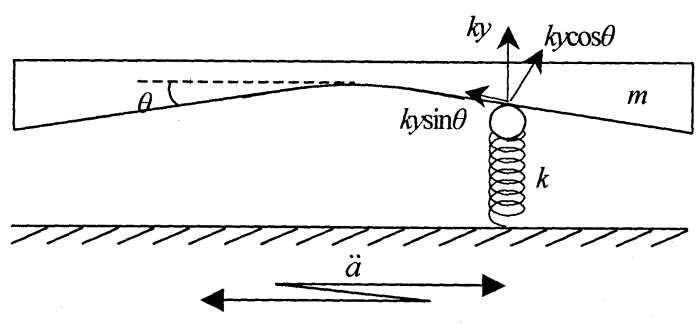

Fig.11 Analytical model

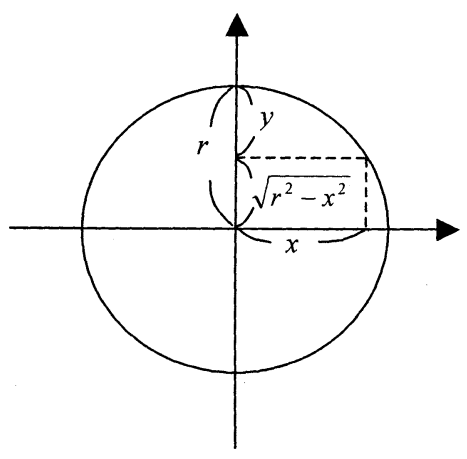

Fig.12 Analytical model (curved surface)

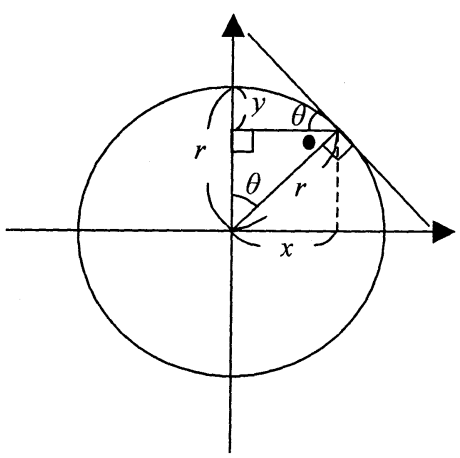

Fig.13 Analytical model (curved surface) 


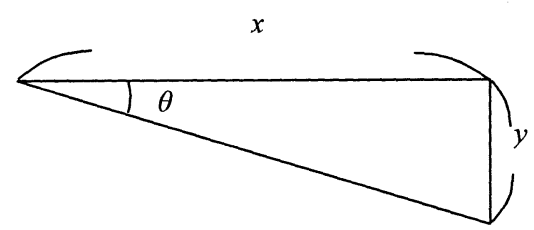

Fig.14 Analytical model (slanting surface)

3.2 解析結果 以上の条件によりシミュレーシ ヨン解析を行った. 入力加速度は, 実験時に得られた 図 7, 図 8 の振動台の入力加速度とする. 解析結果の 一例として，圧縮ばね定数を $4920 \mathrm{~N} / \mathrm{m}$ とし，JMA Kobe NS 波を用いて得られた解析結果を図 15 に, Taft NS波 を用いて得られた解析結果を図 16 に示す。ささらに, 図 17, 図 18 は JMA Kobe NS 波を用いて得られた応答 加速度, 相対変位の最大值を示し, 図 19, 図 20 は Taft NS 波を用いて得られた応答加速度, 相対変位の最 大值を示している. 図 9 の実験結果と図 15 の解析結 果を比較すると，応答加速度波形の振幅には差異が生 じているが，相対変位波形はある程度近い一致が見ら れる. 図 10 の実験結果と図 16 の解析結果を比較する と, 応答加速度波形及び相対変位波形ともに近い一致 が見られ，良好な結果が得られた。 また，図 17, 図 18, 図 19, 図 20 から，どの圧縮ばね定数を用いても, 実験結果と解析結果の誤差は小さく，本解析プログラ ムの信頼性が示された. 以上の実験結果および解析結 果より, 本研究モデルの免震性能が確認された.
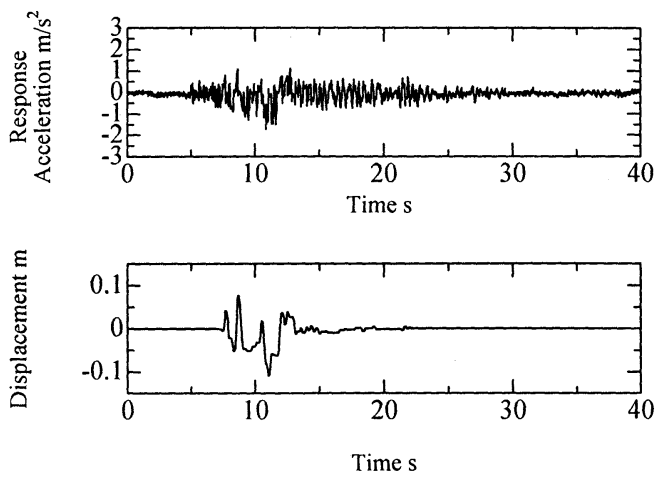

Fig.15 Response acceleration and displacement of analytical result

(JMA Kobe NS, $\max =1.71 \mathrm{~m} / \mathrm{s}^{2}, \quad 0.109 \mathrm{~m}$ )
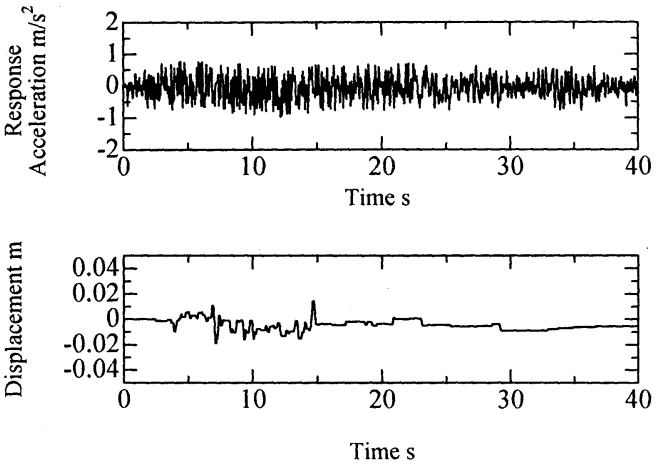

Fig.16 Response acceleration and displacement of analytical result

(Taft NS, $\max =0.97 \mathrm{~m} / \mathrm{s}^{2}, \quad 0.0189 \mathrm{~m}$ )

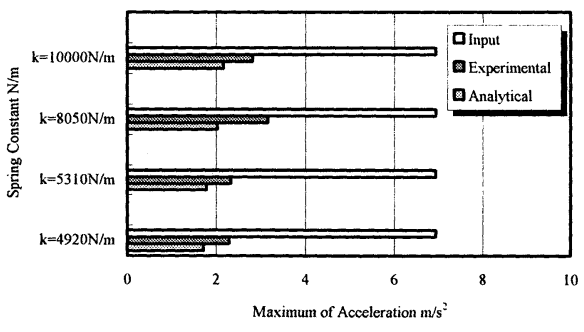

Fig.17 Maximum of Input acceleration and response acceleration (JMA Kobe NS)

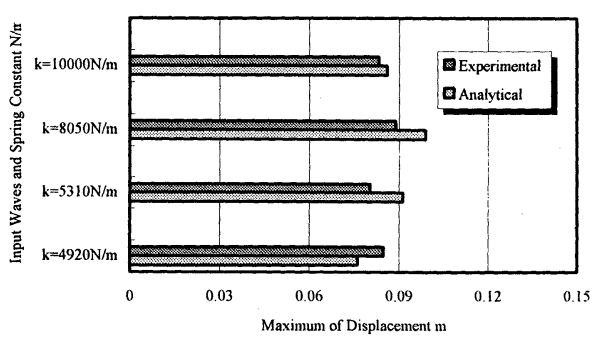

Fig.18 Maximum of displacement (JMA Kobe NS)

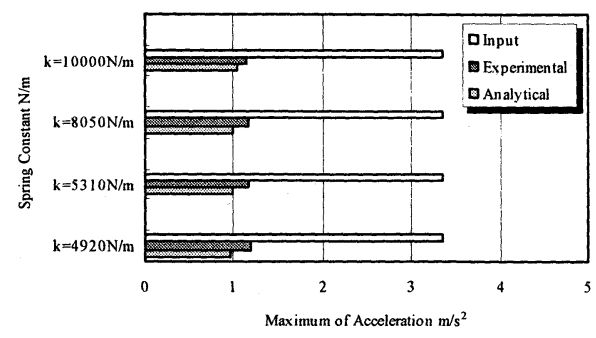

Fig.19 Maximum of Input acceleration and response acceleration (Taft NS) 


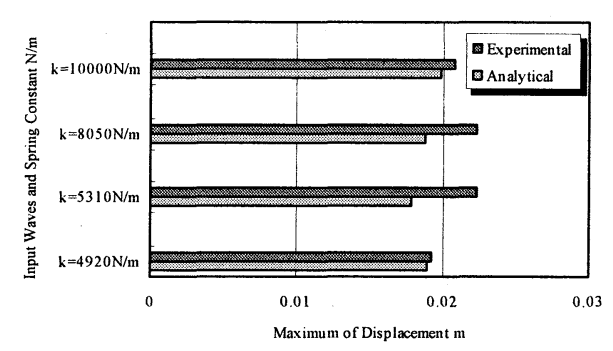

Fig.20 Maximum of displacement (Taft NS)

\section{4. 結言}

（1）免震装置を製作し, 振動実験を行った結果, 応答加速度と相対変位の低減が確認された.

（2）免震装置の解析モデルを作成した.

(3) 実験と同じ条件でシミュレーション解析を行っ た結果, 応答加速度と相対変位の低減が確認 された。

(4) 実験結果と解析結果の比較から, ほぼよい一致 が見られ, 本解析手法の信頼性が示された.

(5) 実験結果および解析結果から, 本研究で提案さ れた免震装置の免震性能が確認された.

\section{文献}

(1) Sakata, T., Okamoto, S., Shibata, K., "Study on Sliding Seismic Isolation Structure Suitable for Light-Weight Houses (Dynamic Responses Analysis of Sliding Bearing with Different Friction Surface)", Proc. of D \& D Conf. JSME, Vol.B(1999), pp.399-402 (in Japanese).

(2) Ohashi, Y., "Earthquake and Isolation Device (New Paradigm of Earthquake-Resistant)", Asakura Publishing, (1996) (in Japanese).

(3) Shintani, M., Yuichi, H., Kotera, T., "Study on Isolation by Friction)", Trans. of JSME, Vol.72, No.747, Series C(2006), pp.388-393, (in Japanese).

(4) Fujita, S., Kizaki, K., "Study on the friction pendulum type isolation device with poly-curvature (1st Report: Fundamental Study on Performance of Isolation)", Proc. of D \& D Conf. JSME, Vol.B(1999), pp.459-462, (in Japanese).

(5) Ueda, S., Fujita, T., Iiba, M., Enomoto, T., "Experiments and Analysis of Roller Type Isolation Device for House", Proc. of D \& D Conf. JSME, CD-ROM, No.15(2005) (in Japanese). 